\title{
The impact of clinical scales in Parkinson's disease: a systematic review
}

\author{
Nikita Aggarwal ${ }^{1 *} \mathbb{D}$, Barjinder Singh Saini ${ }^{1}$ and Savita Gupta ${ }^{2}$
}

\begin{abstract}
Background: Parkinson's disease is one of the non-curable diseases and occurs by the prominent loss of neurotransmitter (dopamine) in substantia nigra pars compacta (SNpc). The main cause behind this is not yet identified and even its diagnosis is very intricate phase due to non-identified onset symptoms. Despite the fact that PD has been extensively researched over the decades, and various algorithms and strategies for early recognition and avoiding misdiagnosis have been published. The objective of this article is to focus on the current scenario and to explore the involvement of various clinical diagnostic scales in the detection of PD.
\end{abstract}

Method: An exhaustive literature review is conducted to synthesize the earlier work in this area, and the articles were searched using different keywords like Parkinson disease, motor/non-motor, treatment, diagnosis, scales, PPMI, etc., in all repositories such as Google scholar, Scopus, Elsevier, PubMed and many more. From the year 2017 to 2021, a total of 451 publications were scanned, but only 24 studies were chosen for a review process.

Findings: Mostly as clinical tools, UPDRS and HY scales are commonly used and even there are many other scales which can be helpful in detection of symptoms such as depression, anxiety, sleepiness, apathy, smell, anhedonia, fatigue, pain, etc., that affect the QoL of pateint. The recognition of non-motor manifests is typically very difficult than motor signs.

Conclusion: This study can give the beneficial research paths at an early stage diagnosis by focusing on frequent inspection of daily activities, interactions, and routine, which may also give a plethora of information on status changes, directing self-reformation, and clinical therapy.

Keywords: Parkinson's disease (PD), Motor and non-motor symptoms, Diagnostic scales, Systematic review

\section{Introduction}

The correct diagnosis and appropriate treatment of brain impairment are needed for effective monitoring of PD. The diagnosing process of brain disorders is tedious and profoundly costly. Parkinson's disorder is one of the major issues in the family of neurodegenerative disorders that essentially influences the population above 60 years. The precise cause of PD is still unfamiliar, but our researchers are working hard to figure out what are the causes behind the lack of dopaminergic neurotransmitters in the

\footnotetext{
*Correspondence: aggarwal.nikita.91@gmail.com

${ }^{1}$ Department of Electronics \& Communication Engineering, Dr. B R

Ambedkar National Institute of Technology, Jalandhar 144011, India

Full list of author information is available at the end of the article
}

SNpc [1]. These dopamine neurons may play a significant function in the control of many brain processes, such as behavioral and voluntary gestures [2]. Basically, SNpc is a part of the basal ganglia that control the body movement signals and works with the cerebellum to send impulses back and forth for movement signals, related to the spinal cord [3]. In addition, the reason for the deficit neurons of $\mathrm{SNpc}$ demonstrates the build-up of proteins (aSyn) into Lewy bodies of nerve cells [4]. Also, it has been observed that PD can occur due to a single or combination of factors like gene mutation, toxins, side-effects of drugs, rural living, trauma, aging, sex, and many more.

The Parkinsonian syndrome (PS) is categorized into motor symptoms (MS) and non-motor symptoms (NMS) as shown in Table 1. Generally, MS appear early than 
NMS, but in some cases NMS may appear early and even earlier than the beginning of MS affirming the diagnosis [5]. In addition, NMS can have a greater influence on the quality of life (QoL) [6] from MS and is associated with significantly less well-being. NMS was seen in about $90 \%$ of patients with PD at all phases of the disease [7]. The social and economic consequences of PD have a considerable impression on a patient's QoL [8]. Because of the progressive appearance of signs [9], prognosis, and therapies vary significantly from other non-degenerative variants in their early stages, identifying management issues for a correct diagnosis is difficult or indecisive $[10,11]$. With increasing clinical experience, the accuracy can be improved and also demonstrated that even the correct identification is missed in approximately $20 \%$ of cases because most of the cases are confused with other disorders [12].

While no particular treatment has been found for PD [13], medications can help to control manifestations. Mostly treatment includes pharmacologic strategies (L-Dopa arrangements recommended with or without other medications) and non-pharmacologic methods (for example workout, physical education, occupational, speech rehabilitations, and nourishment [14]). PD can be treated with verbally guided dopamine precursor, levodopa (L-Dopa) [15] and even with combination of some other agents (COMT receptors, MAO-B agents, dopamine agonists (DA), and nondopaminergic agents [16]). If the condition does not lead to treatment, surgery may be appropriate option. Another alternative is deep brain stimulation (surgery of either subthalamic core or globus pallidus), which showed to be effective in the treatment of patients suffering from PD motor problems [17].

In the diagnosis of early PD detection, there are several ways such as imaging-based, scale-based measurement, signal-based, and computer-aided methods. So, in this systematic review the effect of motor and nonmotor based scales for detection has been discussed and also elaborated with its features. After the brief introduction, the paper is divided into following sections: "Review methodology" explains the methodology of the paper and "Role of clinical scales" covers the role of scales in diagnosis of PD. Section "Discussion" discusses the overview of this systematic review article and research gaps. Lastly, conclusion of the paper is given in "Conclusion".

Table 1 Motor/non-motor symptoms

\begin{tabular}{|c|c|}
\hline Symptom type & Features \\
\hline \multicolumn{2}{|l|}{ Motor symptoms } \\
\hline Bradykinesia [18] & $\begin{array}{l}\text { Affects up to } 98 \% \text { of Parkinson's Patients } \\
\text { Motor planning amplitude disruptions are reduced }\end{array}$ \\
\hline Tremor [19] & $\begin{array}{l}\text { Approximately 75\% of PD patients are affected by tremor } \\
\text { Includes rest tremor, action tremor, and mixed tremor } \\
\text { Trembling of one or both hands at rest is a symptom } \\
\text { Also affects the chin, lips, face, and legs }\end{array}$ \\
\hline Muscular rigidity [20] & $\begin{array}{l}\text { Muscle resistance during passive mobilization is unable to relax normally } \\
\text { Creates muscle pain }\end{array}$ \\
\hline Postural reflex and gait disturbance [21] & $\begin{array}{l}\text { People with PD can fall up to } 40 \% \text { of the time } \\
\text { About } 10 \% \text { of people can experience weekly falls } \\
\text { The number of drop-downs is related to the seriousness of PD } \\
\text { Shorter stride length, which can get shorter over time }\end{array}$ \\
\hline \multicolumn{2}{|l|}{ Non-motor symptoms } \\
\hline Autonomic dysfunction [22] & $\begin{array}{l}\text { Affects } 70 \% \text { to } 80 \% \text { of patients } \\
\text { Have a high level of morbidity and pain } \\
\text { Includes sexual problem, dysregulation of swallowing, gastrointestinal disorders, cardiac regulation } \\
\text { problem, orthostatic hypotension, entrail, and bladder irregularities }\end{array}$ \\
\hline Sleep dysfunction [23] & $\begin{array}{l}\text { Affecting } 64 \% \text { of PD patients } \\
\text { Fatigue, REM sleep pattern disorder, muscle spasms, prolonged morning sleepiness, sleep disorder, and } \\
\text { sleep fragmentation are all forms of sleep disturbances } \\
\text { Sleep dysfunctions are multi-factorial that includes nocturnal and diurnal symptoms } \\
\text { Sleep in PD is characterized by decreased sleep performance and an elevated number of awakenings }\end{array}$ \\
\hline Sensory dysfunction [24] & Includes pain, olfactory disturbance, and visual dysfunction \\
\hline Neuropsychiatric [25] & $\begin{array}{l}\text { Includes depression, anxiety, apathy and psychosis } \\
\text { Despite the lower prevalence rates, roughly } 30-40 \% \text { of patients with PD experience severe depressive } \\
\text { manifests }\end{array}$ \\
\hline
\end{tabular}




\section{Review methodology}

This article investigates the state-of-the-art on clinical scales that are related to PD's detection. The main aim of pertinent literature review is to analyze and identify the different clinical scales from the reported studies in the domain of early PD detection for future research. So, we execute the Preferred Items for Systematic Reviews and Meta-Analyses (PRISMA) [26] methodology for this article and discussed in Fig. 1. We searched total 451 articles with different keywords like Parkinson disease, motor/non-motor, UNDRESS, H\&Y, review, diagnosis, scales, etc., in different repositories such as Google scholar, Scopus, Elsevier, Pub Med and many more. After this step, we removed the duplicate articles and left articles were 406 . The screened articles were analyzed on behalf of title and abstract. Then, filtration criteria were applied that included exclusion-inclusion points. In exclusion criteria, we excluded the articles related to multimodal criteria (means used with some other modality or combination with other processing technique), we analyzed various NMS symptom based articles, UPDRS, review articles (already published), papers in English language and published paper on scales only. Based on these requirements, full-text articles were accessed (104) and lastly, a total 24 selected articles were used for this systematic review.

\section{Role of clinical scales}

For clinical evaluation, valid measuring instruments for rating the severity of disease symptoms, stage of disease, ability to determine everyday functional activities, and symptomatic response to medication are needed for PD therapeutic interventions [13]. Thus, it was probably the discovery of new techniques in the management of PD that led to the design of new scales focusing on specific points of PD based on the required assessment [27]. For the assessment, there are several meaningful MS/NMSbased measurement scales that propose to evaluate the different cardinal manifestations for the early detection of PD. Different community-clinicians use PD rating scales (by assigning a score to them) as a clinical method to evaluate MS/NMS exercises, but the basic scales MDS-UPDRS [28] and HY are mostly used as discussed in Table 2 [29]. It is also observed that these methods are cheapest and convenient-to-use as compared to other methods.

In addition to basic diagnostic scales, there are many other measurement scales that are highly recommended to reach the complexity of NMS [31] and also used to identify the specific symptoms of PD like Depression, Anxiety, Autonomic dysfunction, cognitive dysfunction, Sleep, Apathy, smell, Anhedonia, Fatigue, Pain, etc. (as shown in Table 3). It is noteworthy that non-motor assessment is even more difficult to give a clear clinical

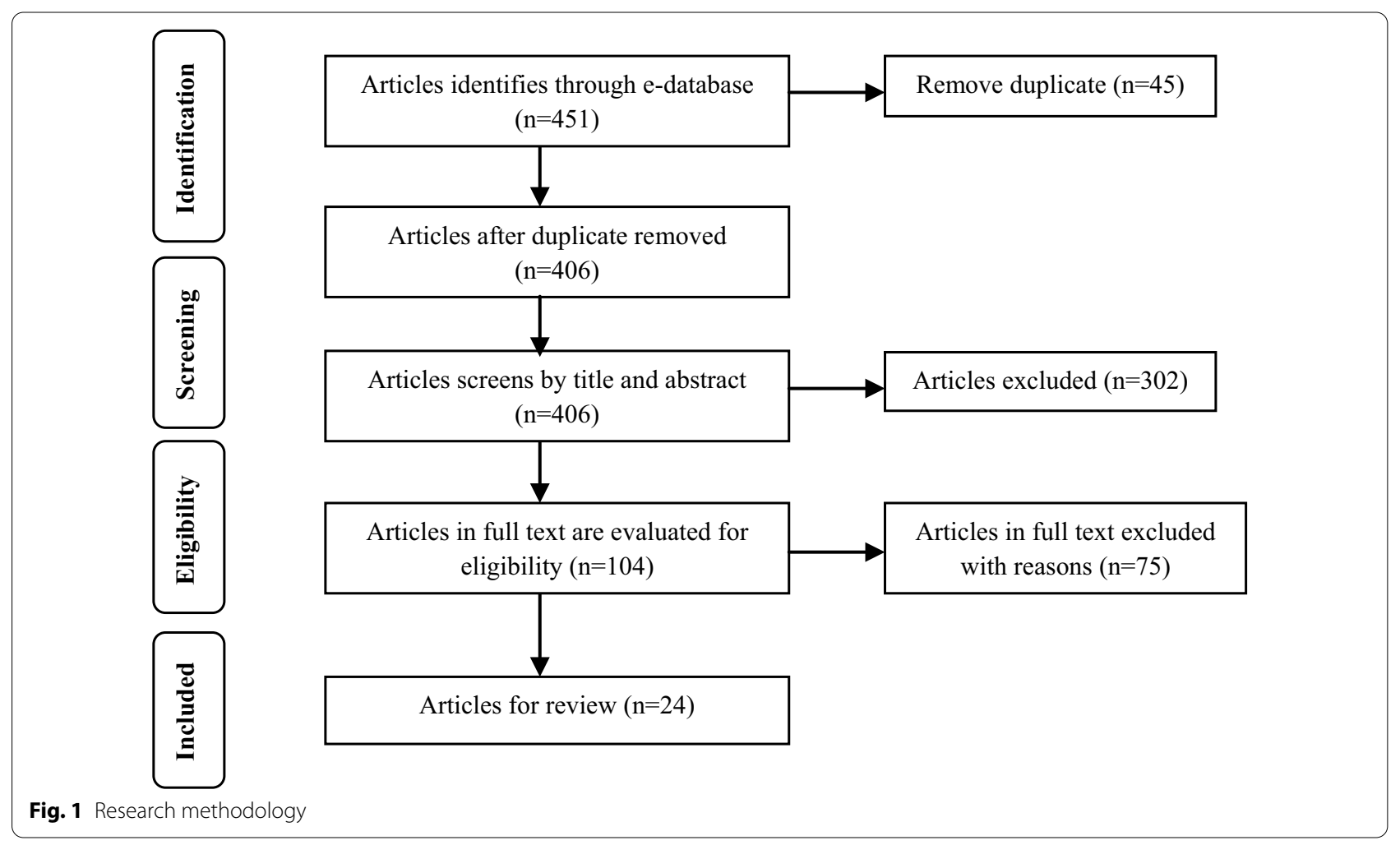




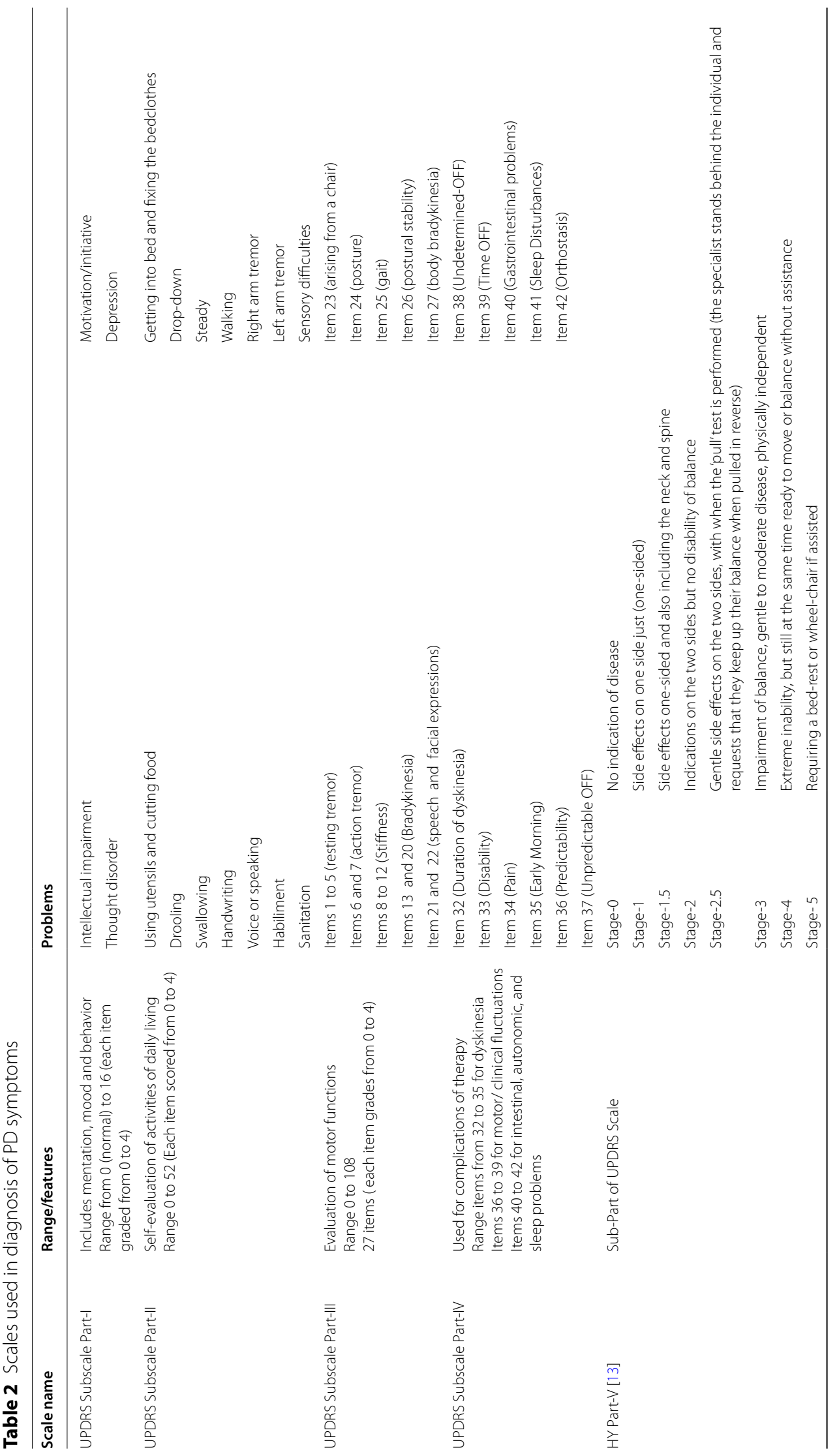




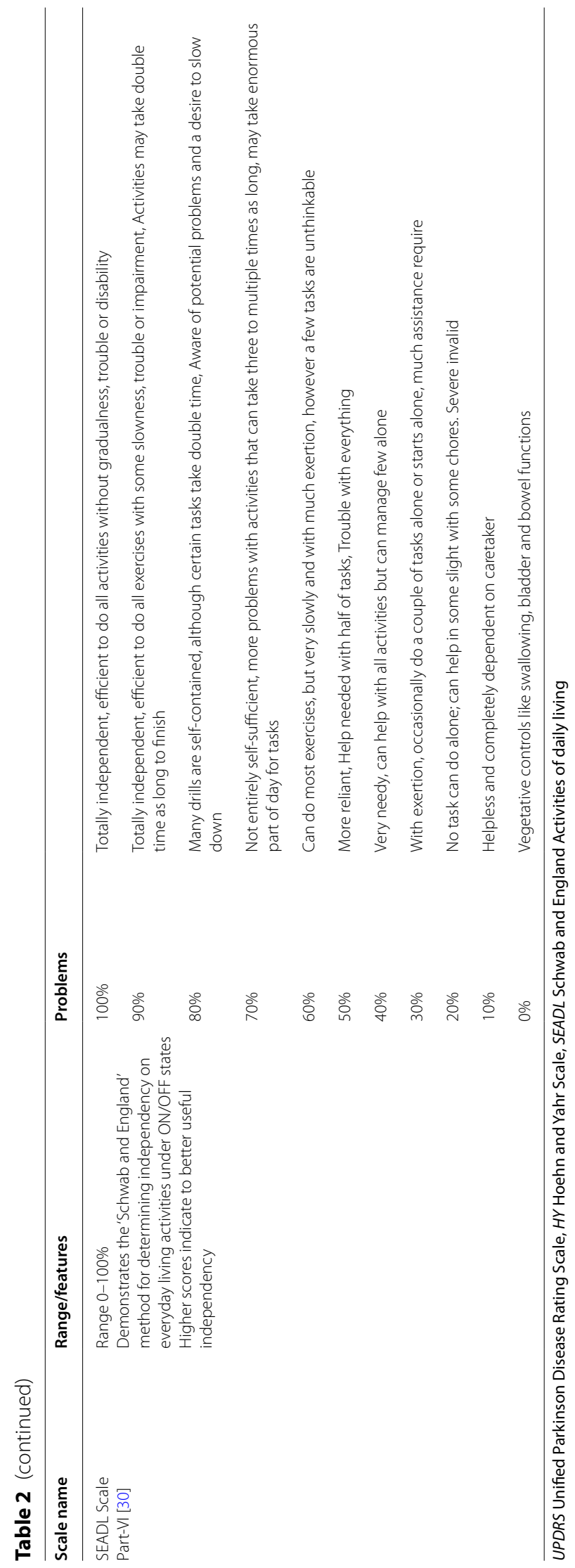


Table 3 Other NMS scales

\begin{tabular}{|c|c|c|c|}
\hline S. no. & NMS problems & $\begin{array}{l}\text { Different } \\
\text { scales of NMS }\end{array}$ & Features \\
\hline \multirow[t]{2}{*}{1} & Monitoring for NMS & NMS-Q & $\begin{array}{l}\text { There are } 30 \text { items in all } \\
\text { Self-sufficient and a yes/no answer }\end{array}$ \\
\hline & & NMS-S & $\begin{array}{l}\text { Physician administered } 9 \text { domains and having } 30 \text { items } \\
\text { Needs rating of frequency }(1-4) / \text { severity responses }(0-3)\end{array}$ \\
\hline 2 & Quality of Life & PDQ-39 & $\begin{array}{l}\text { Assess } 39 \text { item } \\
\text { Clinical administrated and covered by questionnaire }\end{array}$ \\
\hline 3 & Autonomic dysfunction & SCOPA & $\begin{array}{l}\text { Includes } 25 \text { items } \\
\text { No cut-off value is defined }\end{array}$ \\
\hline \multirow[t]{3}{*}{4} & Cognitive dysfunction & PD-CRS & $\begin{array}{l}\text { Getting } 7 \text { activities that are administered by a clinician } \\
\text { Checking for memory issues }\end{array}$ \\
\hline & & SCOPA:CS & Having 10 tasks, clinician-administered \\
\hline & & MoCA & To detect mild cognitive impairment and PD dementia \\
\hline \multirow[t]{4}{*}{5} & Depression & Ham-D & $\begin{array}{l}\text { Multiple versions of scale exist, but commonly version of } 17 \text { items is mostly used } \\
\text { Self-administered, clinician-administered, and semi-structured forms are all available }\end{array}$ \\
\hline & & $\mathrm{BDI}$ & Employs 21 items, self-completed, multiple choice answers \\
\hline & & MADRS & $\begin{array}{l}\text { Consists of } 10 \text { items, clinician-administered } \\
\text { Not usually used }\end{array}$ \\
\hline & & GDS & Anxiety screening service for senior citizens, self-report, yes or no screening instrument \\
\hline 6 & Anxiety & STAI & Diagnosing anxiety and differentiating it from depressive disorders \\
\hline \multirow[t]{6}{*}{7} & Sleep & PDSS & Having 15 items, self-completed \\
\hline & & SCOPA:SS & $\begin{array}{l}\text { Identifying and evaluating the degree of daytime sleepiness } \\
\text { Uses self-completed } 12 \text { items } \\
\text { Looks at signs from the preceding month as well }\end{array}$ \\
\hline & & PSQI & Consists of 19 items, self-completed with monitoring of previous month symptoms \\
\hline & & ESS & $\begin{array}{l}\text { A self-completed 8-item questionnaire with 0-3 rating on each item was used to determine } \\
\text { the degree of daytime sleepiness } \\
\text { For pathologic sleepiness, a cut-off of } 10 / 11 \text { is used }\end{array}$ \\
\hline & & ISCS & Consists of 6 items, clinician-administered \\
\hline & & SSS & Calculating magnitude at a certain point in time \\
\hline \multirow[t]{3}{*}{8} & Apathy & AES & $\begin{array}{l}\text { Based on an } 18 \text {-item Likert scale } \\
4 \text { items scored solely by the patient, } 1 \text { item scored solely by the rater }\end{array}$ \\
\hline & & AS & $\begin{array}{l}\text { Abridged AES, which was developed for PD and has a 4-point Likert scale of } 14 \text { items, was } \\
\text { used in treatment trials } \\
\text { Patient's score (items are read to patient) }\end{array}$ \\
\hline & & LARS & $\begin{array}{l}\text { In therapy trials, } 33 \text { items are used to screen for apathy } \\
\text { Structured interview with yes/no }\end{array}$ \\
\hline 9 & Anhedonia & SHPS & Followed by 14 items, self-completed \\
\hline \multirow[t]{2}{*}{10} & Smell & AHRS & Ability to smell by asking questions \\
\hline & & UPSI & To quantify the olfactory function \\
\hline 11 & Fatigue & FSS & $\begin{array}{l}\text { After reading each phrase, the applicant must circle or round a number between } 1 \text { and } 7 \\
\text { Self-administered, } 9 \text {-item } \\
\text { A low value implies that the argument is not entirely true, while a high value indicates that it is }\end{array}$ \\
\hline \multirow[t]{2}{*}{12} & Pain & DN4 & $\begin{array}{l}\text { Interview problems and physical measurements are used } \\
\text { A score of }>4 \text { was deemed positive on the test }\end{array}$ \\
\hline & & VAS & $\begin{array}{l}\text { To determine the severity of the pain } \\
\text { It varies from } 0 \text { (no pain) to } 10 \text { (extreme pain) }\end{array}$ \\
\hline
\end{tabular}

NMS-Q NMS Questionnaire, NMS-S NMS scale, PDQ-39 PD questionnaire, SCOPA Scales for Outcomes in PD, PD-CRS PD Cognitive Rating Scale, SCOPA-CS SCOPACognitive subscale, MoCA Montreal Cognitive Assessment, Ham-D Hamilton Depression Index, BDI Beck Depression Inventory, MADRS Montgomery-Asberg Depression Rating Scale, GDS Geriatric Depression Scale, STAI State-Trait Anxiety Inventory, PDSS PD Sleep Scale, SCOPA-SS Scales for Outcomes in PD- sleep subscale, PSQI Pittsburgh Sleep Quality Index, ESS Epworth Sleepiness Scale, ISCS Inappropriate Sleep Composite Score, SSS Stanford Sleepiness Scale, AES Apathy Evaluation Scale, AS Apathy Scale, LARS Lille Apathy Rating Scale, SHPS Snaith-Hamilton Pleasure Scale, AHRS Argentina Hyposmia Rating Scale, UPSIT University of Pennsylvania smell identification test, FSS Fatigue Severity Scale, DN4 Douleur Neuropathique-4 Questionnaire, VAS visual analogue scale 
description of than motor issues because it involves a subjective assessment and patient cooperation, which is sometimes difficult to get. These evaluations include the analysis of disease staging, QoL, activities of daily living, impairment, disability, and other specific aspects. In general, the questionnaire-based assessment method used for NMS and those attempting to address whole-complex NMS differs from those specifically for those attempting portions of resolution of side-effects. Still, there is little evidence on the psychometric characteristics of most of these instruments used for this disease, and some are beneficial only for a specific group of individuals [27].

\section{Discussion}

Parkinson's disorder is one of the major issues and occurs due to the death of dopaminergic neurotransmitters of $\mathrm{SNpc}$. The progression of the symptoms often varies from person to person to the diversity of the disease. The influence of PD on a person's life is immense on both social and economic levels. Even, it has been also observed that motor signs appear sooner than non-motor but in some cases, non-motor manifestations may appear early and confirm the diagnosis even before the beginning of motor manifests. The identification management problems for accurate diagnosis are very challenging or indecisive part due to the gradual appearance of symptoms, prognosis, and similarity with other non-degenerative disorders. In general, influenced people are given L-Dopa with agonists or inhibitors.

In early phases, before undergoing medications or scans, scales can help in diagnosis of early symptoms evaluation because these imaging evaluations are expensive and may produce some side-effects. Even these clinical scales can help the researchers and practitioners to start their work with these scales for detection of PD because these are easy to handle and convenient. The scale's assessment depends upon the rating score and it lies between the 5-point range from 0 to $4{ }^{\prime}(0$ ' $=$ no problem, ' 1 ' $=$ mild difficulties, ' 2 ' $=$ moderate difficulties, ' 3 ' $=$ high levels of difficulties, and ' 4 ' $=$ extreme difficulties). The accuracy of scales also depends upon the patients' response because sometimes patient is unable to give answer in that case caretaker may respond. The severity of disease can be evaluated from the total score. Mostly for motor and non-motor symptoms, UPDRS and HY scales are used, but for particular assessment of symptom, there are many other non-motor scales. Secondly, in later stages of Parkinson's disease, these scales can help in providing the information of progression of disease.

In this systematic review process, the motor and nonmotor scales have been discussed. Therefore, it has been analyzed that UPDRS and HY scales are largely used as clinical tools, but also these scales have some limitations which are further modified according to the demand of the nature. Some of the drawbacks have been noted by the Movement Disorders Society (MDS), including vague questions, insufficient instruction, and exclusion of essential components of NMS. Their findings led to the creation of a new version of the MDS-UPDRS, which addresses issues with the UPDRS and allows for improved identification of minor alterations and impairments [32]. Even it is also found that HY staging scale only reflects the motor complications of disease (especially the matter of balance/gait) [29]. There are many other NMS scales for particular symptom identification in PD. The paper has discussed the 12 subtypes of NMS scales; each category has been further including the different types of scales for particular symptom diagnosis.

The first subtype is monitoring for NMS that includes two types of scales (NMSS and NMSQ) and the problems analyzed by these two scales are cardiac, fatigue, apathy, vision issues, memory issues, sexual, gastrointestinal, urinary, and so on [33]. Both the NMSQ and NMSS load grades exhibit a strong inverse relationship with patient's QoL [34]. The second subtype is the quality of NMS that includes PDQ-39 scale which is a clinically and psychometrically admissible indication of the key components of health, functioning, and impairment [35]. The third subtype is autonomic dysfunction that involves SCOPAAUT scale which is a specific instrument designed to assess autonomic function for PD patients and targeting the regions with 7 items of gastrointestinal, 6 items of urinary incontinence, 3 items of cardiovascular, 4 items of thermoregulatory, 1 item of pupillomotor and 4 items of sexual ( 2 for men and 2 for women) [36]. Also these symptoms have great impact on PD patient's daily life functioning [37].

The fourth type is cognitive dysfunction that includes three scales (PD-CRS, MoCA and SCOPA:CS) which is used to access cortical and subcortical functions [38]. PD-CRS: including naming and copy drawing of a clock, verbal memory, attention, working memory, visuo-spatial functions, alternating, and action fluency [39]. The MoCA has also been demonstrated to be effective in distinguishing healthy controls from PD patients with various cognitive stages (no cognitive impairment, moderate cognitive impairment, or dementia) [40]. The fifth subtype involves depression that includes four types of scales (Ham-D, BDI, MADRS, and GDS), the symptom of depression affecting 40\% (approx.) of PD patients [41]. The sixth subpart Anxiety that has one scale STAI, composed of two subscales (STAI-state and STAI-trait) [38]. Anxiety affects $12-57 \%$ of PD patients [42]. The seventh subpart is sleep having six scales (PDSS, SCOPA: SS, PSQI, ESS, ISCS, and SSS) and sleep disturbances affect 
the QoL of PD patient [43]. Sleep disturbances create the problems like insomnia, daytime sleepiness, sleepwalking, and overlap parasomnia [44, 45]. The eighth subpart is Apathy and contains three scales under apathy (AES, AS, and LARS); between 17 and 50\% of PD patients develop apathy during the course of the disease. Apathy affects the behavioral disturbance and also creates the intellectual impairment, level of consciousness, and emotional distress problems [46]. Anhedonia, the ninth component, is described as a reduced ability to enjoy pleasure. It is regarded as a fundamental symptom of severe depression, with $30-40 \%$ of those with PD experiencing substantial depression [47]. The tenth subpart is Smell that includes two scales (AHRS and UPSI). Smell impairment in PD patients ranges from 75 to $95 \%$. The 11th subpart belongs to Fatigue and screened by FSS. Patients are asked to rate how each item describes their fatigue from 1 ("strongly disagree") to 7 point (s) ("strongly agree"). Total FSS score is obtained by dividing the sum of all item scores by 9 [36]. The 12th subpart is Pain that involves two types of scales (DN4 and VAS) which affects around $67.6 \%$ of PD patients. DN4 pain is used to distinguish between the presence and absence of neuropathic pain. On the other hand, VAS identifies the pain score in the last $24 \mathrm{~h}$.

\section{Research gaps}

1. The most common method used in detection is questionnaire-based data analysis, but there is a problem of data inconsistency because sometimes the patient is unable to give an answer or response in that case caretaker can handle or give the response.

2. Even it is found that these scales are not fit for both clinical diagnoses and research because sometimes these are only useful for particular age groups.

3. Furthermore, a large number of scales are invalid in most of the countries where they used, because they were not properly adapted to the circumstances of a foreign society, instead of being simply translated from the original language. No doubt, scale-based analysis is cheapest and convenient to patients but due to non-linearity in data, there should be another alternative for early detection.

4. Although there are several scales in the literature, most of them were developed for other diseases and then tested in PD.

5. Some of the scales need a lot of training before the application.

6. None of the scales is perfect, and it would probably be better to use combined scales even though we know that they overlap in some aspects.

\section{Conclusions}

PD is a non-preventable disorder that affects the quality of patient's life, but the cause behind this has nevertheless been revealed. Therefore, it is important to know the causes, manifestations, and treatment procedures of $\mathrm{PD}$ for better management. Many potential treatments for PD are being developed as a result of the emergence in experimental therapeutics and also there are many ways that can assist an affected person in a major way to meet the needs and survival. This review article offers original and applicable guidelines for PD researchers and practitioners on improving the biomarker for early detection based on the literature. During the review process, the 24 research articles were analyzed from a total of 451 articles. The chosen articles followed the inclusion-exclusion criteria. The article demonstrates the various diagnostic clinical scales of PD. These scales can help the patient for particular symptom diagnosis and all these have huge potential to find the PD on early stages and can also aid to reduce the burden of doctors, side-effects of medications, and patient's expenses in the treatment process.

\begin{abstract}
Abbreviations
UPDRS: Unified Parkinson Disease Rating Scale; HY: Hoehn and Yahr Scale; SEADL: Schwab and England Activities of Daily Living; NMS-Q: NMS questionnaire; NMS-S: NMS scale; PDQ-39: PD questionnaire; SCOPA: Scales for outcomes in PD; PD-CRS: PD Cognitive Rating Scale; SCOPA-CS: SCOPAcognitive subscale; MoCA: Montreal Cognitive Assessment; Ham-D: Hamilton Depression Index; BDI: Beck Depression Inventory; MADRS: MontgomeryAsberg Depression Rating Scale; GDS: Geriatric Depression Scale; STAI: StateTrait Anxiety Inventory; PDSS: PD Sleep Scale; SCOPA-SS: Scales for Outcomes in PD-sleep subscale; PSQI: Pittsburgh Sleep Quality Index; ESS: Epworth Sleepiness Scale; ISCS: Inappropriate Sleep Composite Score; SSS: Stanford Sleepiness Scale; AES: Apathy Evaluation Scale; AS: Apathy Scale; LARS: Lille Apathy Rating Scale; SHPS: Snaith-Hamilton Pleasure Scale; AHRS: Argentina Hyposmia Rating Scale; UPSIT: University of Pennsylvania smell identification test; FSS: Fatigue severity scale; DN4: Douleur Neuropathique-4 questionnaire; VAS: Visual analogue scale.
\end{abstract}

\section{Acknowledgements}

None.

\section{Authors' contributions}

NA: conceptualization, writing — original draft, visualization. BSS: writing review and editing, supervision. SG: writing — review and editing, supervision. All authors read and approved the final manuscript.

Funding

None.

Availability of data and materials

Data sharing is not applicable to this article as no data sets were generated or analyzed during the current study.

\section{Declarations}

Ethics approval and consent to participate

Not applicable.

Consent for publication

Not applicable. 


\section{Competing interests}

The authors report no competing interests.

\section{Author details}

${ }^{1}$ Department of Electronics \& Communication Engineering, Dr. B R Ambedkar National Institute of Technology, Jalandhar 144011, India. ${ }^{2}$ Department of Computer Science Engineering, University Institute of Engineering and Technology, Panjab University, Chandigarh 160014, India.

Received: 22 September 2021 Accepted: 28 November 2021

Published online: 19 December 2021

\section{References}

1. Grover S, Bhartia S, Yadav A, Seeja KR. Predicting severity of Parkinson's disease using deep learning. Procedia Computer Sci. 2018;132:1788-94. https://doi.org/10.1016/j.procs.2018.05.154.

2. Stefanis L. a-Synuclein in Parkinson's disease. Cold Spring Harb Perspect Med. 2012;2(2): a009399. https://doi.org/10.1101/cshperspect.a009399.

3. Chinta SJ, Andersen JK. Dopaminergic neurons. Int J Biochem Cell Biol. 2005;37(5):942-6. https://doi.org/10.1016/j.biocel.2004.09.009.

4. Warner TT, Schapira AH. Genetic and environmental factors in the cause of Parkinson's disease. Ann Neurol. 2003;53(S3):S16-25. https://doi.org/10. 1002/ana.10487.

5. Truong DD, Bhidayasiri R, Wolters E. Management of non-motor symptoms in advanced Parkinson disease. J Neurol Sci. 2008;266(1-2):216-28. https://doi.org/10.1016/j.jns.2007.08.015.

6. Hinnell C, Chaudhuri KR. The effect of non-motor symptoms on quality of life in Parkinson's disease. Eur Neurol Rev. 2009;4(2):29-33. https://doi.org/ 10.17925/ENR.2009.04.02.29.

7. Gökçal E, VeyselEren GR, et al. Motor and non-motor symptoms in Parkinson's disease: effects on quality of life. Archives of Neuropsychiatry. 2017;54(2):143. https://doi.org/10.5152/npa.2016.12758.

8. Cevik F, Kilimci ZH. Analysis of Parkinson's disease using deep learning and word embedding models. Academic Perspective Procedia. 2019;2(3):786-97. https://doi.org/10.33793/acperpro.02.03.86.

9. Prashanth R, Roy SD, Mandal PK, Ghosh S. High-accuracy classification of Parkinson's disease through shape analysis and surface fitting in 1231-loflupane SPECT imaging. IEEE J Biomed Health Inform. 2017;21(3):794-802. https://doi.org/10.1109/JBHI.2016.2547901.

10. Booth TC, Nathan M, Waldman AD, Quigley AM, Schapira AH, Buscombe J. The role of functional dopamine-transporter SPECT imaging in parkinsonian syndromes, part 1. Am J Neuroradiol. 2015;36(2):229-35. https://doi. org/10.3174/ajnr.A3970.

11. Cummings JL, Henchcliffe C, Schaier S, Simuni T, Waxman A, Kemp P. The role of dopaminergic imaging in patients with symptoms of dopaminergic system neurodegeneration. Brain. 2011;134(11):3146-66. https://doi. org/10.1093/brain/awr177.

12. Hiner BC. Differential diagnosis of Parkinson's disease: a new blood test? Clin Med Res. 2006:4(4):246-7. https://doi.org/10.3121/cmr.4.4.246.

13. Perlmutter JS. Assessment of Parkinson disease manifestations. Curr Protoc Neurosci. 2009;49(1):10-1. https://doi.org/10.1002/0471142301. ns1001s49.

14. Radhakrishnan DM, Goyal V. Parkinson's disease: A review. Neurol India. 2018;66(7):26. https://doi.org/10.4103/0028-3886.226451.

15. Alexander GE. Biology of Parkinson's disease: pathogenesis and pathophysiology of a multisystem neurodegenerative disorders. Dialogues Clin Neurosci. 2004:6(3):259-80.

16. Jankovic J, Aguilar LG. Current approaches to the treatment of Parkinson's disease. Neuropsych Dis Treatment. 2008;4(4):743. https://doi.org/10. 2147/ndt.s2006.

17. Armstrong MJ, Okun MS. Diagnosis and treatment of Parkinson disease: a review. JAMA. 2020;323(6):548-60. https://doi.org/10.1001/jama.2019. 22360.

18. Berardelli A, Rothwell JC, Thompson PD, Hallett M. Pathophysiology of bradykinesia in Parkinson's disease. Brain. 2001;124(11):2131-46. https:// doi.org/10.1093/brain/124.11.2131.

19. Gironell A, Pascual-Sedano B, Aracil I, Marín-Lahoz J, Pagonabarraga J, Kulisevsky J. Tremor types in Parkinson disease: a descriptive study using a new classification. Parkinson's Disease. 2018. https://doi.org/10.1155/ 2018/4327597.

20. Baradaran N, Tan SN, Liu A, Ashoori A, Palmer SJ, Wang ZJ, Oishi MM, McKeown MJ. Parkinson's disease rigidity: relation to brain connectivity and motor performance. Front Neurol. 2013;4:67. https://doi.org/10.3389/ fneur.2013.00067.

21. Williams DR, Litvan I. Parkinsonian syndromes. Continuum. 2013;19(5):1189. https://doi.org/10.1212/01.CON.0000436152.24038.e0.

22. Zesiewicz TA, Baker MJ, Wahba M, Hauser RA. Autonomic nervous system dysfunction in Parkinson's disease. Curr Treat Options Neurol. 2003;5(2):149-60. https://doi.org/10.1007/s11940-003-0005-0.

23. Loddo G, Calandra-Buonaura G, Sambati L, Giannini G, Cecere A, Cortell P, Provini F. The treatment of sleep disorders in Parkinson's disease: from research to clinical practice. Front Neurol. 2017;8:42. https://doi.org/10. 3389/fneur.2017.00042.

24. Zhu M, Li M, Ye D, Jiang W, Lei T, Shu K. Sensory symptoms in Parkinson's disease: clinical features, pathophysiology, and treatment. J Neurosci Res. 2016;94(8):685-92. https://doi.org/10.1002/jnr.23729.

25. Aarsland D, Marsh L, Schrag A. Neuropsychiatric symptoms in Parkinson's disease. Mov Disord. 2009;24(15):2175-86. https://doi.org/10.1002/mds. 22589.

26. Moher D, Shamseer L, Clarke M, Ghersi D, Liberati A, Petticrew M, Shekelle $P$, Stewart LA. Preferred reporting items for systematic review and metaanalysis protocols (PRISMA-P) 2015 statement. Syst Rev. 2015;4(1):1-9. https://doi.org/10.1186/2046-4053-4-1.

27. Rissardo JP, Caprara ALF. Parkinson's disease rating scales: a literature review. Ann Movement Disorders. 2020;3(1):3. https://doi.org/10.4103/ AOMD.AOMD_33_19.

28. Holden SK, Finseth T, Sillau SH, Berman BD. Progression of MDS-UPDRS scores over five years in de novo Parkinson disease from the Parkinson's progression markers initiative cohort. Movement Disorders Clin Pract. 2018;5(1):47-53. https://doi.org/10.1002/mdc3.12553.

29. Chaudhuri KR, Rojo JM, Schapira AH, Brooks DJ, Stocchi F, Odin P, Antonini A, Brown RJ, Martinez-Martin P. A proposal for a comprehensive grading of Parkinson's disease severity combining motor and non-motor assessments: meeting an unmet need. PLoS ONE. 2013;8(2): e57221. https://doi. org/10.1371/journal.pone.0057221.

30. https://www.epda.eu.com/about-parkinsons/symptoms/rating-scales, accessed on 7th July 2021.

31. Sung VW, Nicholas AP. Nonmotor symptoms in Parkinson's disease: expanding the view of Parkinson's disease beyond a pure motor, pure dopaminergic problem. Neurol Clin. 2013;31(3):S1-16. https://doi.org/10. 1016/j.ncl.2013.04.013.

32. AlMahadin G, Lotfi A, Zysk E, Siena FL, Mc Carthy M, Breedon P. Parkinson's disease: current assessment methods and wearable devices for evaluation of movement disorder motor symptoms-a patient and healthcare professional perspective. BMC Neurol. 2020;20(1):1-13. https://doi.org/10. 1186/s12883-020-01996-7.

33. van Wamelen DJ, Martinez-Martin P, Weintrau D, Schrag A, Antonini A, Falup-Pecurariu C, Odin P, Ray Chaudhuri K, and International Parkinson and Movement Disorder Society Parkinson's Disease Non-Motor Study Group, 2021. The Non-Motor Symptoms Scale in Parkinson's disease: validation and use. Acta Neurologica Scandinavica, 143(1):3-12. https:// doi.org/10.1111/ane.13336

34. Todorova A, Jenner P, Chaudhuri KR. Non-motor Parkinson's: integral to motor Parkinson's, yet often neglected. Pract Neurol. 2014;14(5):310-22. https://doi.org/10.1136/practneurol-2013-000741.

35. Nilsson MH, Westergren A, Carlsson G, Hagell P. Uncovering indicators of the international classification of functioning, disability, and health from the 39-item Parkinson's disease questionnaire. Parkinson's Disease. 2010. https://doi.org/10.4061/2010/984673.

36. Yu QJ, Yu SY, Zuo LJ, Lian TH, Hu Y, Wang RD, Piao YS, Guo P, Liu L, Jin Z, Li $L X$. Parkinson disease with constipation: clinical features and relevant factors. Sci Rep. 2018;8(1):1-9. https://doi.org/10.1038/s41598-017-16790-8.

37. Rodriguez-Blazquez, C., Forjaz, M.J., Frades-Payo, B., de Pedro-Cuesta, J., Martinez-Martin, P. and Longitudinal Parkinson's Disease Patient Study (Estudio longitudinal de pacientes con enfermedad de Parkinson-ELEP) Group. Independent validation of the scales for outcomes in Parkinson's disease-autonomic (SCOPA-AUT). Eur J Neurol. 2010;17(2):194-201. https://doi.org/10.1111/j.1468-1331.2009.02788.x. 
38. Santangelo G, Lagravinese G, Battini V, Chiorri C, Siciliano M, Abbruzzese $G$, Vitale C, Barone P. The Parkinson's disease-cognitive rating scale (PDCRS): normative values from 268 healthy Italian individuals. Neurol Sci. 2017;38(5):845-53. https://doi.org/10.1007/s10072-017-2844-6.

39. Rosca EC, Simu M. Parkinson's disease-cognitive rating scale for evaluating cognitive impairment in Parkinson's Disease: a Systematic review. Brain Sci. 2020;10(9):588. https://doi.org/10.3390/brainsci10090588.

40. Fengler S, Kessler J, Timmermann L, Zapf A, Elben S, Wojtecki L, Tucha $\mathrm{O}$, Kalbe E. Screening for cognitive impairment in Parkinson's disease: improving the diagnostic utility of the MoCA through subtest weighting. PLoS ONE. 2016;11(7): e0159318. https://doi.org/10.1371/journal.pone. 0159318.

41. Schrag A, Barone P, Brown RG, Leentjens AF, McDonald WM, Starkstein S, Weintraub D, Poewe W, Rascol O, Sampaio C, Stebbins GT. Depression rating scales in Parkinson's disease: critique and recommendations. Mov Disord. 2007;22(8):1077-92. https://doi.org/10.1002/mds.21333.

42. Yang HJ, Ahn JH, Lee J, Lee WK, Lee J, Kim Y. Measuring anxiety in patients with early-stage Parkinson's disease: Rasch analysis of the State-Trait Anxiety Inventory. Front Neurol. 2019;10:49. https://doi.org/10.3389/fneur. 2019.00049.

43. Kurtis MM, Balestrino R, Rodriguez-Blazquez C, Forjaz MJ, Martinez-Martin P. A review of scales to evaluate sleep disturbances in movement disorders. Front Neurol. 2018;9:369. https://doi.org/10.3389/fneur.2018.00369.

44. Stefani A, Högl B. Sleep in Parkinson's disease. Neuropsychopharmacology. 2020;45(1):121-8. https://doi.org/10.1038/s41386-019-0448-y.

45. Kim EJ, Baek JH, Shin DJ, Park HM, Lee YB, Park KH, Shin DH, Noh Y, Sung $\mathrm{YH}$. Correlation of sleep disturbance and cognitive impairment in patients with Parkinson's disease. J Movement Disorders. 2014;7(1):13. https://doi.org/10.14802/jmd.14003.

46. Szatmari S, Illigens BMW, Siepmann T, Pinter A, Takats A, Bereczki D. Neuropsychiatric symptoms in untreated Parkinson's disease. Neuropsychiatr Dis Treat. 2017;13:815. https://doi.org/10.2147/NDT.S130997.

47. Loas G, Godefroy O. Hedonic deficits in Parkinson's disease: is consummatory anhedonia specific? Front Neurol. 2014;5:24. https://doi.org/10.3389/ fneur.2014.00024.

48. Oppo V, Melis M, Melis M, Tomassini Barbarossa I, Cossu G. "Smelling and tasting" Parkinson's disease: Using senses to improve the knowledge of the disease. Front Aging Neurosci. 2020;12:43. https://doi.org/10.3389/ fnagi.2020.00043.

49. Padua L, Briani C, Jann S, Nobile-Orazio E, Pazzaglia C, Morini A, Mondelli M, Ciaramitaro P, Cavaletti G, Cocito D, Fazio R. Validation of the Italian version of the Neuropathic Pain Symptom Inventory in peripheral nervous system diseases. Neurol Sci. 2009;30(2):99-106. https://doi.org/10.1007/ s10072-009-0025-y.

\section{Publisher's Note}

Springer Nature remains neutral with regard to jurisdictional claims in published maps and institutional affiliations.

\section{Submit your manuscript to a SpringerOpen ${ }^{\circ}$ journal and benefit from:}

- Convenient online submission

- Rigorous peer review

- Open access: articles freely available online

- High visibility within the field

- Retaining the copyright to your article

Submit your next manuscript at $\gg$ springeropen.com 